\title{
Presencia de circovirus porcino tipo 2 en hatos porcinos de Baja California, México
}

\author{
Presence of porcine circovirus type 2 in porcine herds of Baja California, Mexico \\ Sergio Gómez G. ${ }^{1}$, Gilberto López V. ${ }^{1,3}$, Francisco Monge N. ${ }^{1}$, José Herrera R. ${ }^{1}$, \\ Gerardo Medina B. ${ }^{1}$, Alma Tamayo S. ${ }^{1}$, Jonathan Arauz C. ${ }^{2}$
}

\section{Resumen}

El objetivo de este estudio fue detectar la presencia de circovirus porcino tipo 2 (PCV2) en hatos porcinos de Baja California, México, empleando la técnica de reacción en cadena de la polimerasa (PCR). Se colectaron 97 muestras de sangre de cerdos procedentes de 26 granjas. El ADN se extrajo a partir de la capa leucoplaquetaria y las muestras fueron agrupadas en 19 grupos de cinco muestras y uno de dos muestras para el análisis de PCR. Se utilizaron cebadores específicos para amplificar un fragmento de 264 pares de bases del ORF2 de PCV2 utilizando como control positivo una vacuna comercial. El fragmento viral se detectó en el 15\% (3/20) de los grupos analizados. Este es el primer reporte en el que se evidencia la presencia de circovirus porcino tipo 2 en Baja California.

Palabras clave: circovirus; detección; México; PCR

\section{AbSTraCT}

The aim of this study was to detect the presence of porcine circovirus type 2 (PCV2) in pig herds of Baja California, Mexico, using the polymerase chain reaction (PCR) technique. Blood samples ( $\mathrm{n}=97$ ) were collected from 97 pigs in 26 farms. The DNA was extracted from the buffy coat and the samples were grouped into 19 groups of five samples and one of two samples for PCR analysis. Specific primers were used to amplify a PCV2 ORF2 fragment of 264 base pairs and using a commercial vaccine as a positive control. The viral fragment was detected in 15\% (3/20) of the groups. This is the first report in which the presence of porcine circovirus type 2 in Baja California is evidenced.

Key words: circovirus; detection; Mexico; PCR

\footnotetext{
${ }^{1}$ Instituto de Investigaciones en Ciencias Veterinarias, Universidad Autónoma de Baja California, México

${ }^{2}$ Facultad de Medicina, Universidad Autónoma de Baja California, México

${ }^{3}$ E-mail: gilbertolopez@uabc.edu.mx
}

Recibido: 15 de enero de 2019

Aceptado para publicación: 29 de agosto de 2019 
El circovirus porcino pertenece a la familia Circoviridae, presenta una cadena simple de ADN circular de 18000 nucleótidos con dos marcos de lectura abierta (ORF) que codifican para la replicasa y la cápside viral (Meng, 2013).

El circovirus porcino tipo 2 (PCV2) es conocido como un patógeno universal, habiéndose confirmado su presencia en la mayoría de los países con crianza porcina (Baebko et al., 2012). Es un virus ampliamente involucrado en el desarrollo del síndrome multisistémico posdestete (PMWS) (Blomström et al., 2016), así como en enfermedades tales como el complejo de la enfermedad respiratoria porcina (PRDC), donde participa principalmente con el virus del Síndrome Reproductivo y Respiratorio Porcino (PRRSV) y Mycoplasma hyopneuoniae (Chae, 2016). A este grupo de padecimientos se les conoce como enfermedades asociadas a circovirus porcino (PCVAD) (Anoopraj et al., 2015). La vía más frecuente de transmisión es por la ruta oronasal (Segalés, 2012), diseminándose por todo el organismo y excretado por secreciones orales, respiratorias, orina y heces (Opriessnig et al., 2007). Los signos clínicos más comunes son debilidad, aumento de la frecuencia de signos respiratorios e incremento de la tasa de mortalidad (Opriessnig y Halbur, 2012).

En México existe evidencia de la presencia del PCV2 desde 1973 a través de estudios serológicos retrospectivos (RamírezMendoza et al., 2009); sin embargo, aunque los reportes sobre la presencia de este agente viral provienen de las regiones de mayor producción porcina (Bedolla et al., 2018), la presencia de este virus no ha sido reportada en el estado de Baja California. Por lo anterior, el objetivo de este estudio fue detectar la presencia del PCV2 empleando la técnica de PCR a partir de muestras de ADN de cerdos procedentes de hatos porcinos de Baja California.
Se realizó un estudio transversal por conveniencia entre septiembre de 2016 y agosto de 2017 en las instalaciones de 26 productores de cerdos adscritos al Comité Estatal Sistema Producto Porcino de Baja California, México. El estudio incluyó 26 granjas de tipo familiar (Cuadro 1), habiéndose colectado 97 muestras de sangre en tubos evacuados con anticoagulante EDTA (BD, Franklin Lakes, New Jersey, USA) de la vena yugular de cerdos machos y hembras de pie de cría con edades entre 1 y 4 años, siguiendo el procedimiento descrito por HoltgrewBohling (2016). Los animales se encontraban aparentemente en buen estado de salud.

Las muestras se almacenaron en refrigeración a $4{ }^{\circ} \mathrm{C}$ durante $24 \mathrm{~h}$ para permitir la sedimentación de los componentes sanguíneos. La capa leucoplaquetaria fue colectada por aspiración (200-300 $\mu \mathrm{l})$, procediéndose de inmediato a la extracción del ADN utilizando los reactivos PureLink Genomic DNA Mini Kit (Invitrogen, Carlbad, California, USA) siguiendo las instrucciones del fabricante. El ADN fue reconstituido en un volumen final de $50 \mu 1$ empleando la solución de rehidratación suministrada con los reactivos y se almacenó a $-20^{\circ} \mathrm{C}$ hasta el momento de las pruebas de PCR.

Cuadro 1. Muestras de sangre recolectadas por granja porcina según localidad

\begin{tabular}{lcc}
\hline Localidad & $\begin{array}{c}\text { Granjas } \\
(\mathrm{n})\end{array}$ & $\begin{array}{c}\text { Muestras } \\
(\mathrm{n})\end{array}$ \\
\hline Ensenada & 5 & 27 \\
Mexicali & 6 & 27 \\
Tecate & 2 & 13 \\
Tijuana & 2 & 6 \\
San Quintín & 9 & 18 \\
Valle de Mexicali & 2 & 6 \\
\hline Total & 26 & 97 \\
\hline
\end{tabular}


Considerando que el objetivo del trabajo fue detectar el ADN viral, y que no se contaba con recursos suficientes para realizar los estudios individuales, se decidió agrupar las muestras en grupos de cinco individuos. Las muestras fueron analizadas de acuerdo como fueron registradas en la bitácora de ingreso al laboratorio, sin discriminar por el lugar de origen de esta.

\section{Oligonucleótidos para PCV2}

Los oligonucleótidos utilizados para la detección de PCV2 fueron los reportados por Larochelle et al. (1999) a partir del ORF2. El oligonucleótido de sentido positivo fue denominado PCV2F con secuencia 5'-TAG GTT AGG GCT GTG GCC TT-3' y el oligonucleótido de sentido negativo fue denominado PCV2R con secuencia 5' -CCG CAC CTT CGG ATA TAC TG-3', los cuales producen un producto amplificado de 264 pares de bases (pb). Estos oligonucleótidos fueron sintetizados por ADN Sintético S.A. P.I. de C.V. (Guanajuato, México) y fueron reconstituídos con agua grado biología molecular y diluidas a una concentración de $100 \mu \mathrm{M}$ (solución de reserva) y posteriormente a $10 \mu \mathrm{M}$ como solución de trabajo. Las soluciones de oligonucleótidos de reserva y de trabajo fueron almacenadas a $-20{ }^{\circ} \mathrm{C}$ hasta el momento de las pruebas de PCR.

\section{PCR para PCV2}

Las muestras se agruparon en 19 grupos de 5 animales y un grupo de 2 animales. Las reacciones de PCR se realizaron empleando una mezcla maestra con un volumen final de $20 \mu \mathrm{l}$ que contenía $75 \mathrm{mM}$ Tris- $\mathrm{HCl}$ (pH 8.8), $20 \mathrm{mM}$ de sulfato de amonio, $0.01 \%$ Tween 20, $1.5 \mathrm{mM}$ de cloruro de magnesio, $200 \mu \mathrm{M}$ de dNTPs, $7.5 \%$ de DMSO, 1.25 unidades de ADN polimerasa, $1 \mu \mathrm{l}$ de cada oligonucleótido y $1 \mu \mathrm{l}$ del extracto de ADN obtenido de las muestras de capa leucoplaquetaria. Como control positivo se utilizó un extracto de ADN obtenido a partir de la vacuna comercial Fostera ${ }^{\circledR}$ PCV (Zoetis) que contiene virus inactivado. Como controles negativos se utilizó la mezcla maestra sin ADN templete y agua grado biología molecular en tubos separados. La amplificación se realizó en un equipo Thermo Hybaid PCR Express Bybaid PCYLOO1 Issue 3 Thermal Cycler HBPX110 aplicando un ciclo inicial de desnaturalización de $5 \mathrm{~min}$ a $94{ }^{\circ} \mathrm{C}$, seguido de 40 ciclos con 1 min de desnaturalización a $94{ }^{\circ} \mathrm{C}, 1 \mathrm{~min}$ de hibridación a $60.0^{\circ} \mathrm{C}$ y un ciclo final de extensión de 1 min segundos a $72{ }^{\circ} \mathrm{C}$. El producto amplificado del PCR fue visualizado por electroforesis en gel de agarosa al 3\%. Las muestras se consideraron positivas cuando se formó una banda de ADN amplificado de aproximadamente 264 pares de bases $(\mathrm{pb})$.

\section{Resultados}

Las pruebas de PCR muestran que 3 de los 20 (15\%) conjuntos de muestras resultaron positivos para amplificación de la región ORF2 de PCV2, confirmando la presencia de este virus en el estado de Baja California. Los grupos de muestras que resultaron positivos contenían muestras provenientes de todas las regiones muestreadas, excepto del Valle de Mexicali. Los resultados del PCR se muestran en la Figura 1. El tamaño de los fragmentos de PCR fue de $264 \mathrm{pb}$.

\section{Discusión}

Este estudio representa el primer reporte sobre la presencia del PCV2 en hatos porcinos del Estado de Baja California. Es importante señalar que aunque los resultados muestran que la distribución de la enfermedad está generalizada en la región, no se detectaron signos clínicos asociados a enfermedad por PCV2 en los animales muestreados. Segalés (2012) indica, asimismo, que la infección por PCV2 se encuentra ampliamente distribuida, siendo la infección subclínica la presentación más frecuente. 


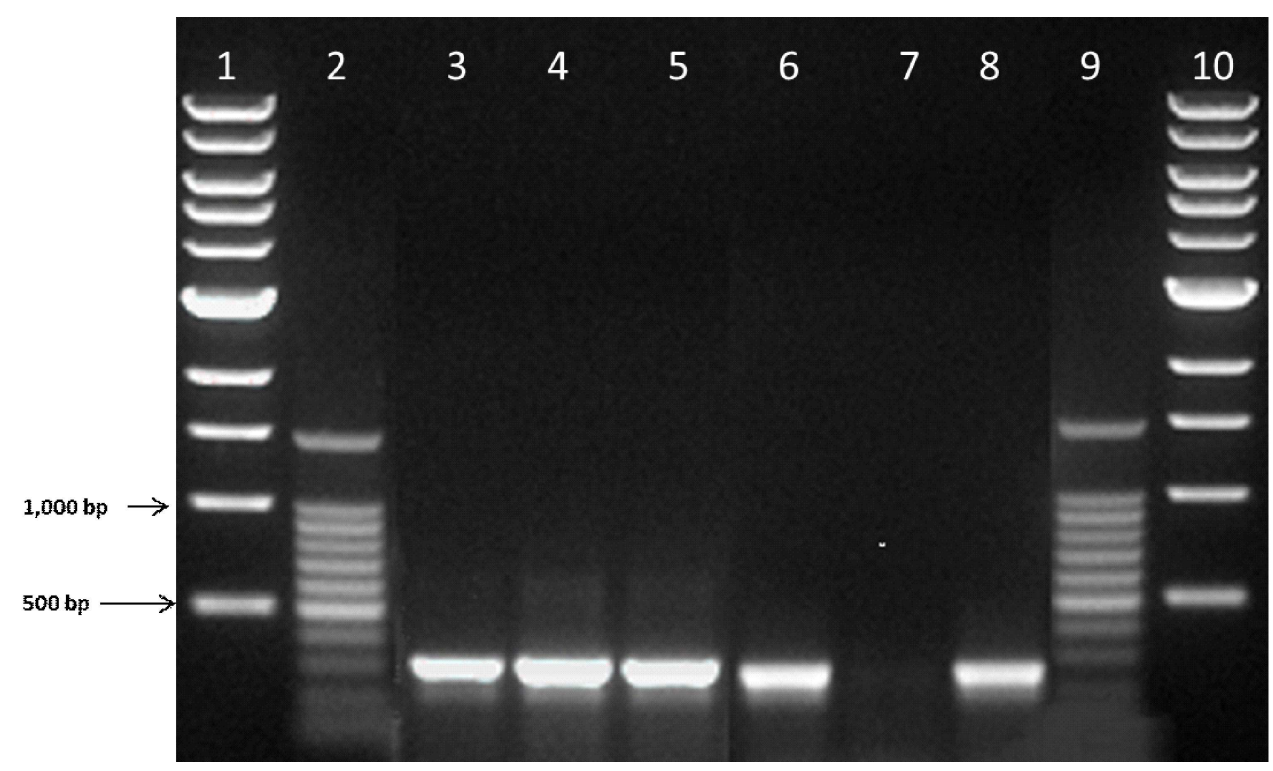

Figura 1. Resultado de la amplificación del gen ORF 2 del OCV-2 en las muestras de sangre colectadas a partir de cerdos de Baja California. Líneas 1 y 10: marcador de $1 \mathrm{~kb}$ de ADN; líneas 2 y 9: marcador de 100 pb de ADN; líneas 3 y 8: control positivo; línea 4: grupo positivo\#1; línea 5: grupo positivo \#2; línea 6: grupo positivo \#3; línea 7: control negativo

Los productores porcinos de la zona reportaron que no utilizan vacunas contra PCV2, ya que la ausencia de signos clínicos no justifica la instrumentación de un programa de vacunación contra esta enfermedad (Boletín SIVE, 2017). Considerando que la enfermedad está presente en Baja California es necesario realizar estudios epidemiológicos transversales con el fin determinar la prevalencia, distribución y los posibles factores de riesgo asociados a la enfermedad en los hatos porcinos para identificar la magnitud del problema y poder establecer medidas de prevención y control.

\section{Literatura Citada}

1. Anoopraj R, Rajkhowa TK, Cherian S, Arya RS, Tomar N, Gupta A, Ray $P K$, et al. 2015. Genetic characterization and phylogenetic analysis of PCV2 isolates from India: indications for emergence of natural inter-genotypic recombinants. Infect Genet Evol 31: $25-$ 32. doi: 10.1016/j.meegid.2015.01.006

2. Baebko P, Kristensen CS, Larsen LE. 2012. Porcine Circovirus diseases: a review of PMWS. Transbound Emerg Dis 59: 60-67. doi: 10.1111/j.18651682.2011.01288.x

3. Bedolla LF, Trujillo OME, Mendoza ES, Quintero $R V$, Alonso MR, Ramírez-Mendoza H, SánchezBetancourt JI. 2018. Identification and genotyping of porcine Circovirus type II (PCV2) in Mexico. Virus Dis 29: 385389. doi: 10.1007/s13337-018-0460-6

4. Boletín SIVE Informa 2017. 2017. CDMX: Servicio Nacional de Sanidad, Inocuidad y Calidad Agroalimentaria. [Internet]. Disponible en: https:// www.gob.mx/senasica/documentos/ boletin-sive-informa-2017

5. Blomström AL, Fossum C, Wallgren P, Berg M. 2016. Viral metagenomic analysis displays the co-infection situation in healthy and PMWS affected pigs. Plos 
ONE 11: e0166863. doi: 10.1371/ journal.pone. 0166863

6. Chae C. 2016. Porcine respiratory disease complex: Interaction of vaccination and porcine Circovirus type 2 , porcine reproductive and respiratory virus, and Mycoplasma hyopneumoniae. Vet J 212: 1-6. doi: 10.1016/ j.tvj1.2015.10.030

7. Holtgrew-Bohling K. 2016. Porcine clinical procedures. In: Holtgrew-Bohling $\mathrm{K}$ (ed). Large animal clinical procedures for veterinary technicians. $3^{\text {rd }}$ ed. USA: Elsevier Mosby. p 619-630.

8. Larochelle R, Antaya M, Morin M, Magar R. 1999. Typing of porcine Circovirus in clinical specimens by multiplex PCR. J Virol Methods 80: 6975. doi: 10.1016/S0166-0934(99)00032-4

9. Meng XJ. 2013. Porcine Circovirus type 2 (PCV2): pathogenesis and interaction with the immune system. Annu Rev Anim Biosci 1: 43-64. doi: 10.1146/annurev-animal-031412-103720
10. Opriessnig T, Meng XJ, Halbur PG. 2007. Porcine Circovirus type 2 associated disease: update on current terminology, clinical manifestations, pathogenesis, diagnosis, and intervention strategies. J Vet Diagn Invest 19: 591615. doi: 10.1177/104063870701900601

11. Opriessnig T, Halbur PG. 2012. Concurrent infections are important for expression of porcine Circovirus associated disease. Virus Res 164: 2032. doi: 10.1016/j.virusres.2011.09.014

12. Ramírez-Mendoza H, Castillo-Juárez H, Hernández J, Correa P, Segalés J. 2009. Retrospective serological survey of Porcine Circovirus-2 infection in Mexico. Can J Vet Res 73: 21-24.

13. Segalés J. 2012. Porcine Circovirus type 2 (PCV2) infections: clinical signs, pathology and laboratory diagnosis. Virus Res 164: 10-19. doi: 10.1016/ j.virusres.2011.10.007 